\title{
Construction of Regional Pattern for Ecological Security in Regional Development
}

\author{
Yang Yang ${ }^{1}$, Liu $\mathrm{Hao}^{2}$, Gu Chunguang ${ }^{1, *}$ and $\mathrm{Li} \mathrm{Nan}^{3}$ \\ ${ }^{1}$ College of Technology Management, UCAS, Beijing 100049, P.R. China \\ ${ }^{2}$ Department of Sociology, Peking University, Beijing 100871, P.R. China \\ ${ }^{3}$ National Science Library, CAS, Beijing 100190, P.R. China
}

\begin{abstract}
This newly proposed concept, the Regional Pattern for Ecological Security (RPES), provided an integrated strategy for implementing ecosystem restoration and biodiversity conservation at regional scale. Based on the concept and its theoretical basis, the designing principles and a preliminary method were put forward. With the method, the Regional Pattern for Ecological Security of the area along the Yangtze River in Anhui Province (the AYRAP) was constructed. In terms of the ecological features of the AYRAP, an ecological security pattern should be established, consisting of 3 ecological sources, 6 ecological corridors and numerous ecological patches and wedges.
\end{abstract}

Keywords: Distortion regional pattern for ecological security, Ecological feature, Ecological source, The ecological service importance.

\section{INTRODUCTION}

Since the 20th century, human society is in constant development. First, the basic necessities like foods and transport, have changed into leisure. Second, changes have been brought about in the scope of social production and human activities. Manual work is replaced by machines. A number of industries and jobs are being created with the development of technology. Third, the changing morphological objective world, accelerating urbanization, the increasing city landoccupancy, the expansion of infrastructure, the dropping forest, the developed artificial river system, and various other advancements show that the landscape form of the global ecosystem has changed and environmental problems are being expanded from regions to the whole world $[1,2]$.

The serious environmental problems in the world are a threat to the sustainable development of human society. Protecting ecological security has become the pressing social need [3]. Ecological security (eco logical security) refers to the safety of natural and semi-natural ecosystems in the narrow sense, which reflect the integrity and health of the whole ecosystem. Broadly, it refers to aspects of human life, health, happiness, fundamental rights, livelihood security sources, the necessary resources, social order and the human ability to adapt to changing environment, which can be under nonthreatening condition, including natural ecological security, economic and ecological security and social ecological security, forming a composite artificial ecological security system.

Generally, ecological security [4] refers to the health status of ecological systems and other environmental factors

*Address correspondence to these authors at the College of Technology Management, UCAS, Beijing 100049, P.R. China; Tel: +358-6-3247476; Fax:+358-6-3247457; E-mail: hunter2011@foxmail.com like climate, water, air, soil, etc. at country or regional scale. It is the threshold of exploitation of natural resources. Ecosystem management is currently more focused on the restoration mechanisms of degraded ecosystems and discussion related to ecological economics, policy and social issues. There is still a problem on how to adjust recovery measures and management strategies on the space area, so regional ecology environmental issues can be solved. For regional environmental problems and interference sources, reasonable construction of regional ecological patterns to implement management measures against ecological risk is the new requirement of regional ecological environment protection, and is also the key to the success of ecosystem management.

Therefore, the concept of "the regional pattern for ecological security" has been proposed.

\section{RPES CONSTRUCTION METHOD}

"The regional pattern for ecological security" is defined as the regional spatial pattern which can protect and restore biodiversity [5-6], maintain the integrity of the ecosystem structure and processes, achieve effective control and continuous improvement of the regional ecological environment on the basis of excluded interference for regional environmental problems. The proposal of regional ecological security pattern provides a new way for adaptive ecosystem management. The regional pattern for ecological security pays attention to regional-scale environmental problems, relationship of patterns and processes, rating scale issues, impact of interference, biodiversity conservation [7], ecosystem restoration, socio-economic development [8], and the comprehensive integration of these aspects. So the theoretical foundation involves content from multiple subjects like landscape ecology, disturbance ecology, conservation biology, restora- 
tion ecology, ecological economics, ecological ethics, and ecological systems theory. The results of these subjects provide useful reference for the regional pattern of ecological security study.

The RPES study being systematic and having a direct approach significantly points to the ecological problems and is focused on the ecological restoration and biological conservation at regional scale. It emphasizes on the restoration and configuration of degraded eco systems, the maintenance of eco system health, the optimization of landscape pattern, and the spatial pattern adjustment adapted to the development of society and economics at regional scale. The spatial pattern visualizes the strategies of eco system management, and ensures the security of ecological pattern and process as well as their integration at regional scale.

A region's ecological security pattern is the basis and guarantee of its sustainable development. For complex regional environmental problems, regional spatial pattern is designed to protect and restore biodiversity, and maintain the integrity of the ecosystem structure process, achieving effective control and continuous improvement of the regional ecological environment on the basis of excluded interference in the planning stage. Through adjusting the relationship between human and human, human and nature, the balance of consumer demand, commodity production, resources consumption, environmental impact, and social order are set and organized [9].

Consulting the methods and experiences of other related designs, like landscape eco-planning, security patterns, spatial explicit landscape ecological model, public participation, scenarios, and the regional pattern for ecological security design method with 5 steps has been proposed.

\subsection{Landscape Pattern and Functional Assessment}

Landscape indices are commonly used to characterize landscape pattern characteristics, which are the general quantitative indicators having an account of landscape components, spatial composition, including three levels: individual plaques, plaque type and overall landscape [10]. There are some common landscape indices like landscape richness index, landscape diversity index, landscape dominance index, landscape evenness index, landscape shape index, contagion index, and separation index [11].

\subsubsection{Landscape Richness Index}

$$
R=\mathrm{n}
$$

$\mathrm{n}$ is the number of plaque type in landscape.

To compare between different types of landscape, relative richness and richness density are used.

$$
\begin{aligned}
& R_{\mathrm{r}}=\frac{n}{n_{\max }} \\
& R_{\mathrm{d}}=\frac{n}{A}
\end{aligned}
$$

$R_{\mathrm{r}}$ is relative richness, and $R_{\mathrm{d}}$ is richness density.

$\mathrm{n}_{\max }$ is the maximum of plaque type in landscape.
$\mathrm{A}$ is the area of the landscape.

\subsubsection{Landscape Diversity Index}

Common landscape diversity index includes 2 forms:

1. Shannon-Weaver diversity index

$$
L=-\sum_{i=1}^{\mathrm{m}} P_{i} \ln \left(P_{i}\right)
$$

$P_{\mathrm{i}}$ is the probability of plaque type $\mathrm{i}$ in the landscape.

$\mathrm{m}$ is the number of plaque type in the landscape.

2. Simpson diversity index

$$
L^{\prime}=1-\sum_{i=1}^{\mathrm{m}} P_{i}^{2}
$$

The diversity index is decided by plaque richness and uniformity of each plaque type on the area distribution. If the $L$ is higher, the composition of landscape is more complicated.

\subsubsection{Landscape Dominance Index}

It refers to the role of different types of patches in the landscape.

$$
D=L_{\max }+\sum_{i=1}^{\mathrm{m}} P_{i} \ln \left(P_{i}\right)
$$

$L_{\max }$ is the maximum of landscape diversity index.

$P_{\mathrm{i}}$ is the probability of plaque type $\mathrm{i}$ in the landscape.

$\mathrm{m}$ is the number of plaque type in the landscape.

The higher $D$ refers to the more important patches in the landscape.

\subsubsection{Landscape Evenness Index}

It refers to the distribution degree of different patches of landscape in area.

$E=\frac{L}{L_{\max }}=\frac{-\sum_{\mathrm{i}=1}^{m} P_{i} \ln \left(P_{i}\right)}{\ln (n)}$

$L$ is Shannon-Weaver diversity index, $L_{\max }$ is the maximum of it

\subsubsection{Landscape Shape Index}

It refers to the shape complexity degree of the overall landscape (all patches).

$$
L S I=\frac{0.25 E}{\sqrt{A}}
$$

$E$ is the total length of all the patches in the landscape.

$A$ is the area of the landscape.

\subsubsection{Contagion Index}

It refers to the aggregation degree of different types of plaques. 
$F=F_{\max }+\sum_{\mathrm{i}=1}^{\mathrm{n}} \sum_{\mathrm{j}=1}^{\mathrm{n}} P_{\mathrm{ij}} \ln \left(P_{\mathrm{ij}}\right)$

$F_{\max }$ is the maximum of contagion index $[2 \ln (\mathrm{n})]$

$\mathrm{n}$ is the number of plaque type in the landscape

$P_{\mathrm{i}}$ is the probability of plaque type $\mathrm{i}$ adjacent to plaque type $\mathrm{j}$ in the landscape

$F^{\prime}$ is used to compare different landscapes.

$F^{\prime}=\frac{F}{F_{\max }}=1+\frac{\sum_{\mathrm{i}=1}^{\mathrm{n}} \sum_{\mathrm{j}=1}^{\mathrm{n}} P_{\mathrm{ij}} \ln \left(P_{\mathrm{ij}}\right)}{2 \ln (\mathrm{n})}$

\subsection{Ecological Problems Analysis}

Under the presence of certain environmental problems in the region, by analyzing the regional landscape pattern, function, and associated ecosystems, the information such as the scope of strength causes and processes of the ecological problems can be obtained, so that measures can be proposed to solve these problems.

\subsection{Evaluation of Ecosystem}

Through the study of ecological service function theory, Shegaodi used CVM investigation assessment methods, adjusted the value of ecosystem services and established the ecological service value of each type land in the unit area, as shown in Table 1.

The ecological service value of each type land is calculated as follows:

$V_{\mathrm{i}}=P_{\mathrm{i}} * A_{i}$

$V_{\mathrm{i}}$ is the ecological service value of each type land.

$P_{\mathrm{i}}$ is the ecological service value coefficient of each type land in the unit area.

$A_{\mathrm{i}}$ is the area of each type land.
The value of ecosystem services in different types of landscape is calculated.

\subsection{Ecological Services Analysis}

Using quantitative methods in ecological research, services function and health of ecosystem are calculated;

The main problems of ecosystem function are identified and the state of biodiversity is evaluated to recognize the relationship between ecosystem conditions and regional environmental problems.

\subsection{RPES Design}

Based on the pattern and process principles and the overall planning goals, regional ecological security pattern with ability to optimize constantly is created.

The regional ecological security pattern concerned about ecological security issues in this region under the analysis with the basis of the above stages, guided by the principle of natural and heterogeneous, the scheme is proposed which can achieve different levels of ecological safety.

To implement the landscape function network in space, Cost distance Model is adopted (Fig. 1).

In the migration of species, different landscape elements or land use produce a certain resistance. The work to overcome this resistance is Accumulative cost distance.

$A=\frac{1}{2} \sum_{\mathrm{i}=1}^{\mathrm{n}}\left(\mathrm{c}_{\mathrm{i}}+\mathrm{c}_{\mathrm{i}+1}\right)$

$A=\frac{\sqrt{2}}{2} \sum_{\mathrm{i}=1}^{\mathrm{n}}\left(\mathrm{c}_{\mathrm{i}}+\mathrm{c}_{\mathrm{i}+1}\right)$

Accumulative cost distance of every landscape unit in the space to the nearest ecological sources is calculated:

means the Resistance of pixel I, means the Resistance of pixel $i+1$, is the number of pixels,

means the distance of every landscape unit to the nearest ecological sources.

Table 1. The ecological service value of each type land in the unit area.

\begin{tabular}{|c|c|c|c|c|c|c|}
\hline & Farmland & Forest & Lawn & River and lake & Wetland & Desert \\
\hline Food Production & 450.2 & 150.21 & 200.56 & 238.02 & 158.58 & 7.55 \\
\hline Materials production & 168.52 & 1383.56 & 154.65 & 160.9 & 98.04 & 16.51 \\
\hline Gas regulation & 305.52 & 1890.16 & 660.54 & 235.2 & 1158.31 & 25.22 \\
\hline Climate regulation & 485.32 & 1857.48 & 692.43 & 956.64 & 6147.16 & 55.75 \\
\hline Hydrological regulation & 365.58 & 1900.65 & 674.72 & 8585.28 & 6003.2 & 28.69 \\
\hline Waste Treatment & 620.35 & 750.89 & 574.92 & 6815.33 & 6593.42 & 120.48 \\
\hline Soil conservation & 675.84 & 1795.61 & 1085.65 & 168.95 & 916.03 & 69.03 \\
\hline biodiversity Maintenance & 475.62 & 2056.45 & 864.89 & 1540.5 & 1589.12 & 160.82 \\
\hline Entertainment Culture & 80.04 & 964.5 & 400.41 & 1894 & 2106.93 & 99.76 \\
\hline Total & 3626.99 & 12749.51 & 5308.77 & 20594.82 & 24770.79 & 583.81 \\
\hline
\end{tabular}




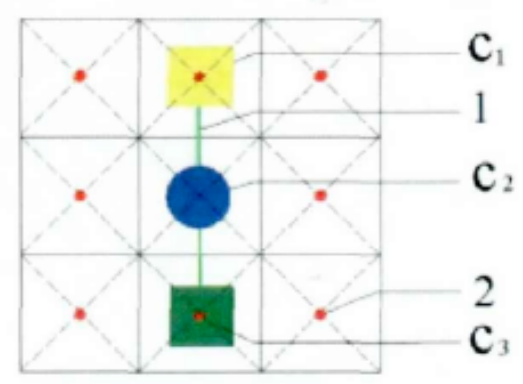

Fig. (1). The function of cost distance model.

When the pixel moves in vertical or horizontal direction, reference (11) is adopted. When it moves diagonally, (12) is used to calculate.

According to the method in Accumulative cost distance model, using the GRID function of ArcGIS to calculate cyclically the accumulative cost, distance of every landscape unit is counted, and spatial distribution of landscape function network is designed.

\section{RPES CONSTRUCTION IN THE AYRAP}

A region's ecological security pattern is the basis and guarantee of its sustainable development. In its establishment, an active role is needed to be played in controlling detrimental disturbance and exercising profitable disturbance, thus achieving coordination of the ecosystem and the socioeconomic system. In the rapidly developing regions, vigorous human activities bring great pressure to the ecosystem, and a harmonious ecological pattern is needed which can protect the stability of regional ecosystem and guarantee the regional sustainable development by horizontal linkage of the ecological space and the urban space.

\subsection{Outline of the AYRAP}

The area along the Yangtze River in Anhui Province (the AYRAP) is taken as an example.

This area is in the transition zone between subtropical and warm temperate with high ecosystem diversity and good natural environment. The areas altitude above $200 \mathrm{~m}$ accounts for $22.2 \%$ of the total land area, with wood area accounting for $31 \%$, water and wetlands accounting for $7.8 \%$.

\subsubsection{Ecological Problems in the AYRAP}

1. With the rapid economic development, natural ecosystems in this region have developed artificial ecosystem and semi- artificial ecosystem. Species diversity and other ecosystem services have declined. Distribution of forest ecosystems with high biodiversity is not balanced, focusing on the south of this region and low mountains in the west. Only 11 counties contain forest covering more than $30 \%$ of the land.

2. Plain in this region is artificial ecosystem based on agriculture and towns. Between the mountains and hills and plains along the river, urban development and ecological space are distributed as parallel strips, having a lack of corridors and green buffer zone.

\subsubsection{The Importance of Ecosystem Services}

Ecosystem services are the conditions and functions beneficial to human survival and development in ecosystems and ecological processes. According to the ability, value, and effect of the ecosystem services, these are the different levels which provide the key to protect ecological security patterns.

According to Table 2, three levels of distributions are divided as being very important, important and generally important. And different levels of distributions are marked by three colors, as shown in Fig. (2).

The very important distributions are mostly in the southern and western AYRAP, the mainstream of the Yangtze River and the wetland around Chao Lake.

\subsubsection{Economic Development Potentialities Analysis}

Economic and social development of area along the rivers is one of the goals in ecological security pattern construction. According to landscape richness index, landscape dominance index, and difference in space, three ecological source regions are obtained, with an area of $22,000 \mathrm{~km}$, accounting for $35 \%$ of the whole region.

- The economic development potentiality is measured from three aspects of integrated development costs, development effectiveness and economic resources.

Fig. (3) shows that the distributions with high economic development potentialities are Hefei urban, Maanshan urban, Wuhu urban, Tongling urban and Anqing urban. The west and south of this region are lower.

Table 2. The eco-service value of different land use types in the AYRAP.

\begin{tabular}{|c|c|c|}
\hline Land use type & Area $/ \mathbf{k m}^{2}$ & $\begin{array}{c}\text { eco-service value } \\
\qquad 10^{4} \mathrm{CNY}^{*} \mathrm{a}^{-1}\end{array}$ \\
\hline Building land & 19453.1 & 0 \\
\hline River and lake & 8549.5 & 18015.064 \\
\hline Forest & 5843.2 & 7379.3773 \\
\hline Garden & 1154.8 & 1458.3972 \\
\hline Farmland & 24876.4 & 8826.1467 \\
\hline Lawn & 3154.7 & 1653.3783 \\
\hline
\end{tabular}




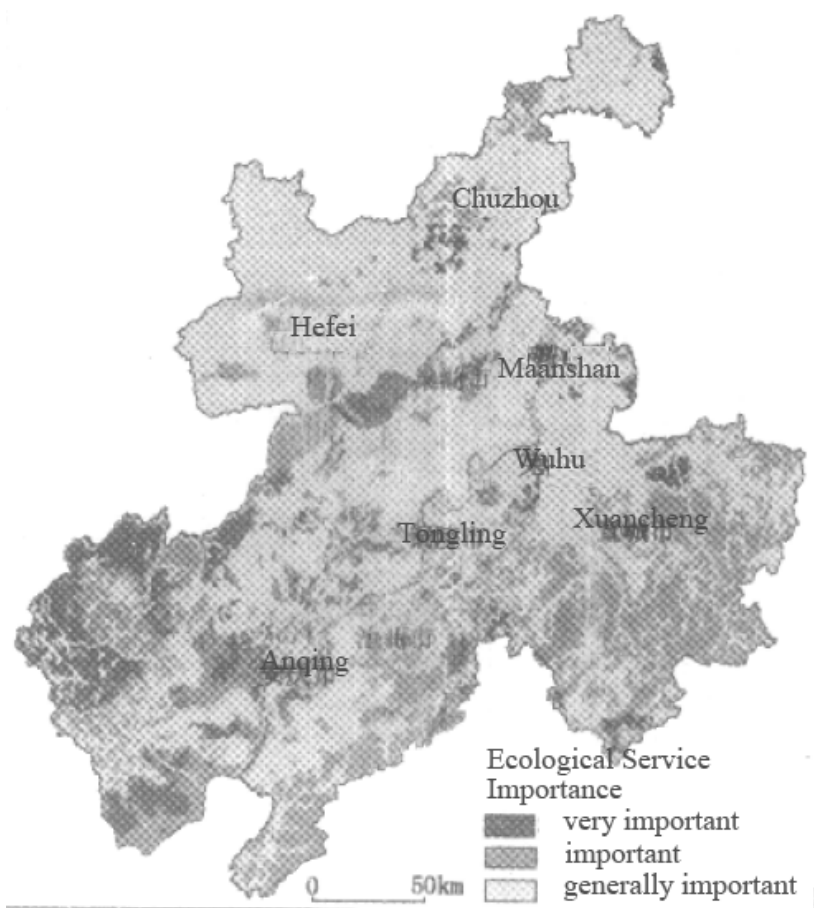

Fig. (2). The distribution of the ecological service importance in the AYRAP.

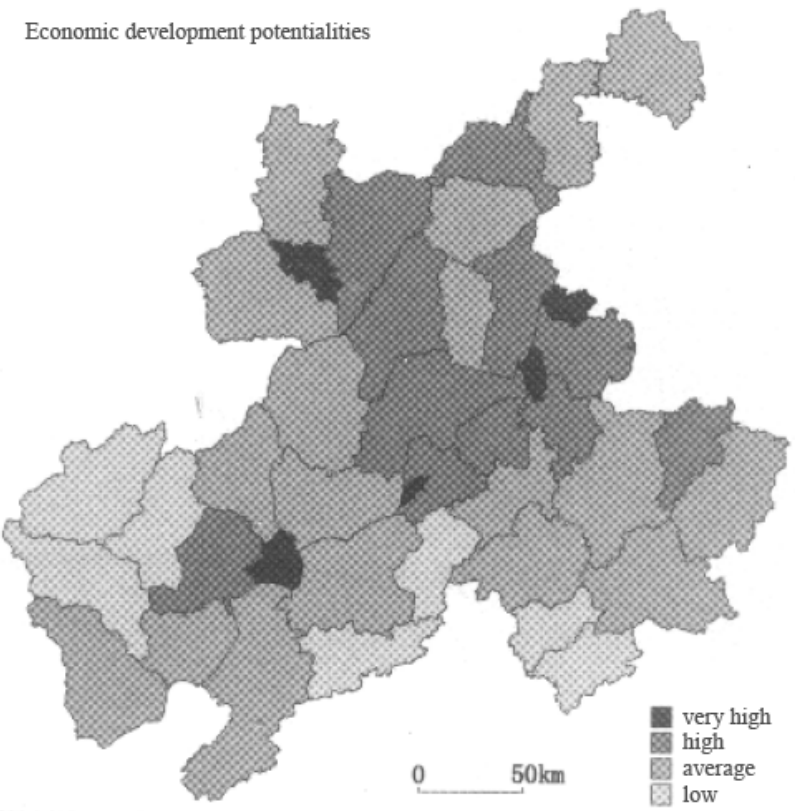

Fig. (3). The distribution of economic development potentialities in the AYRAP.

\subsection{Ecological Source Analysis}

Through an analysis of eco-sensitivity and ecological service importance, this article finds that the areas that need special ecological protection are the mountainous areas in the southern and western AYRAP, the mainstream of the Yangtze River and the wetland around Chao Lake.

Hilly ecological source region in the south, with an area of $13475 \mathrm{~km} 2$, is the biggest ecological source region in this area. Some rivers as Qiupu River, Qingge River and Zhang River originate from this region. So it is important to protect this region to prevent Soil Erosion Geological disasters and the loss of biodiversity.
Hilly ecological source region in the west, with an area of $5705 \mathrm{~km}$, having six reservoirs, provides ecological services for the western region along the river.

Lake Hill Ecological source region in the center with major Chao Lake connects with hilly ecological source region in the south by Yangtze River, protecting a large area development.

\subsection{Ecological Corridors Analysis}

The construction of seven ecological corridors focuses on the sides of major rivers and roads; the main ecological source region, important ecological plaque and the industry along the rivers are connected. These corridors, about 50- 
$100 \mathrm{~m}$ in width, horizontally link the ecological sources and patches and the areas of intensive development of urban industries, forming a stabilized pattern of the ecological space and the urban space.

1. Yangtze River Corridor: the most important Ecological Corridor, connecting 3 Ecological source regions with other 6 Ecological Corridors. It provides Ecological Services of Water security and biodiversity.

2. Shuiyang River Corridor: connecting the hilly ecological source region in the south with Maanshan region.

3. Qingye River Corridor: connecting the hilly ecological source region in the south with $\mathrm{Wu}$ Lake region.

4. Qiufu River Corridor: connecting the hilly ecological source region in the south with Chi State region.

5. Wan River Corridor: connecting the Hilly ecological source region in the west with Anqing region.

6. Yuxi River Corridor: connecting the Lake Hill Ecological source region in the center with $\mathrm{Wu}$ Lake region.

\subsection{Ecological Patches and Wedges}

Ecological patches and wedges distributed in important development zones and urban development areas are linked to ecological sources and corridors. These help to add the function of ecological sources and corridors to the towns and are composed of hills, woodland, wetlands, farmlands and gardens.

\section{CONCLUSION}

With the new method, the Regional Pattern for Ecological Security of the area along the Yangtze River in Anhui Province (the AYRAP) has been constructed, consisting of 3 ecological sources, 6 ecological corridors and numerous ecological patches and wedges with respect tothe ecological features of the AYRAP.

The varied human requirement to ecosystem services is the root reason for implementing the ecosystem management. Therefore, it should be realized not only by the means of social, economic, cultural, moral, law, and regularity methods, but also the need to be consistent to developing demands of human society to ecosystem services. The RPES study will play a key role in dealing with regional ecological and environmental problems; therefore it has a brighter future in ecological restoration and biological conservation.

\section{CONFLICT OF INTEREST}

The authors confirm that this article content has no conflict of interest.

\section{ACKNOWLEDGEMENTS}

This work is supported by the Key Project of Guangxi Social Sciences, China (No.gxsk201424), the Education Science fund of the Education Department of Guangxi, China (No.2014JGA268), and Guangxi Office for Education Sciences Planning, China (No.2013C108).

\section{REFERENCES}

[1] W. Yanglin, "A study on landep and landed of weinan district," Journal of Natural Resources, vol. 4, 1995.

[2] O. Paul, E. Steingröver, and S. Van Rooij, "Ecological networks: a spatial concept for multi-actor planning of sustainable landscapes," Landscape And Urban Planning, vol. 75, no. 3, pp. 322-332, 2006.

[3] P. Stephan, R. Ennos, and Y. Golding, "Modeling the environmental impacts of urban land use and land cover change - a study in Merseyside, UK," Landscape and Urban Planning, vol. 71, no. 2, pp. 295-310, 2009.

[4] R. L. Eaton, P. H. Geoffrey, and J. Laurie, "Footprints on the landscape: An environmental appraisal of urban and rural living in the developed world," Landscape and Urban Planning, vol. 83, no. 1, pp. 13-28, 2012.

[5] G. Piero, and C. Shine, "European strategy on invasive alien species," Convention on the Conservation of European Wildlife and Habitats (Bern Convention). No. 18-137. Council of Europe, 2011.

[6] R. H. G. Jongman, "Ecological networks, from concept to implementation," Landscape Ecological Applications in Man-Influenced Areas, Springer Netherlands, pp. 57-69, 2007.

[7] B.Paul, "Toward best practices for developing regional connectivity maps," Conservation Biology, vol. 25, no. 5, pp. 879-892, 2011 .

[8] C. J. Carroll, R. Dunk, and A. Moilanen, "Optimizing resiliency of reserve networks to climate change: multispecies conservation planning in the Pacific Northwest, USA," Global Change Biology, vol. 16, no. 3, pp. 891-904, 2010.

[9] H. Esbah, "Analyzing landscape changes in the Bafa Lake Nature Park of Turkey using remote sensing and landscape structure metrics," Environmental Monitoring and Assessment, vol. 165, no. 14, pp. 617-632, 2010.

[10] C. S. Gillies, L. B. Hawthorne, and C. C.St. Clair, "Fine-scale movement decisions of tropical forest birds in a fragmented landscape," Ecological Applications, vol. 21, no. 3, pp. 944-954, 2011.

[11] T. Li, Fragmentation of China's landscape by roads and urban areas," Landscape Ecology, vol. 25, no. 6, pp. 839-853, 2013. 